Editorial

\title{
Digital Mis/Disinformation and Public Engagement with Health and Science Controversies: Fresh Perspectives from Covid-19
}

\author{
An Nguyen ${ }^{1, *}$, Daniel Catalan-Matamoros ${ }^{2}$ \\ ${ }^{1}$ Department of Communication and Journalism, Bournemouth University, Poole, BH12 1JJ, UK; \\ E-Mail: anguyen@bournemouth.ac.uk \\ 2 Department of Communication Studies, University Carlos III of Madrid, 28903 Madrid, Spain; \\ E-Mail: dacatala@hum.uc3m.es \\ * Corresponding author
}

Submitted: 15 June 2020 | Published: 26 June 2020

\begin{abstract}
Digital media, while opening a vast array of avenues for lay people to effectively engage with news, information and debates about important science and health issues, have become a fertile land for various stakeholders to spread misinformation and disinformation, stimulate uncivil discussions and engender ill-informed, dangerous public decisions. Recent developments of the Covid-19 infodemic might just be the tipping point of a process that has been long simmering in controversial areas of health and science (e.g., climate-change denial, anti-vaccination, anti-5G, Flat Earth doctrines). We bring together a wide range of fresh data and perspectives from four continents to help media scholars, journalists, science communicators, scientists, health professionals and policy-makers to better undersand these developments and what can be done to mitigate their impacts on public engagement with health and science controversies.
\end{abstract}

\section{Keywords}

anti-5G; anti-vaccination; Covid-19; conspiracy theories; disinformation; healh controversies; infodemic; misinformation; science controversies

\section{Issue}

This editorial is part of the issue "Health and Science Controversies in the Digital World: News, Mis/Disinformation and Public Engagement" edited by An Nguyen (Bournemouth University, UK) and Daniel Catalan (University Carlos III of Madrid, Spain).

(C) 2020 by the authors; licensee Cogitatio (Lisbon, Portugal). This article is licensed under a Creative Commons Attribution 4.0 International License (CC BY).

\section{1. "The First True Social-Media Infodemic"}

Anyone with basic school education and in their right mind would be able to laugh at the bizarre idea of a biological virus spreading through mobile phone networks. Things might become a little more complicated with the claim that radiation from such networks suppresses the immune system against the virus, but it takes only a few clicks to find a reputable health advice source to refute it. Yet, as the novel coronavirus takes hold and wreaks havocs across the world, these two unfounded claims have been able to convince many people to break lockdown rules, pouring onto the street to smash and torch hundreds of $5 \mathrm{G}$ phone masts in many countries - from Australia and New Zealand to the UK, Ireland, Finland, Sweden, Belgium, the Netherlands and Italy (Cerulus, 2020; Lewis, 2020). The World Health Organisation (WHO) had to urgently place the $5 \mathrm{G}$ conspiracy theories on top of its coronavirus myth-busting page.

Much research needs to be done before a full answer can be found regarding why and how something seemingly unthinkable like that could happen. But most observations and analyses have so far pointed to one crucial factor: the powerful role of digital media, especially online social networks, in facilitating and fostering mis/disinformation about health and science. These platforms-especially Facebook with 2.5 billion users and YouTube with two billion as of April 2020 (Clement, 
2020)-allow information to be used, produced, saved and shared at one's discretion, without any hindering or fear (Vestergaard \& Nielsen, 2019). While they open new avenues for lay publics to engage with news, information and debates about health and science issues that shape their private and public lives, these media blur the line between the good and the bad, the scientific and the unscientific, and the true and the false. The link between $5 G$ and coronavirus, with its ensuing arson attacks, is the culmination of this information chaos in a time of an unprecedented crisis. As profound uncertainty rises, limited scientific knowledge and understanding about the new virus is at odds with a panicked public's thirst for information and advice, creating a void for unchecked news, unsubstantiated claims and fabricated stories to fill.

Needless to say, the 5G-coronavirus link is only one of numerous pieces of mis/disinformation fueled by digital social media during this pandemic. As the threats to other countries from the outbreak in China began to loom large in January 2020, observers quickly witnessed the global surge of all sorts of coronavirus-related mis/disinformation-from mere rumours and misleading interpretations of facts to fabricated videos and conspiracy theories-around its origin, symptoms, development, prevention and treatment measures, government responses/strategies and so on. Just to name a few:

- The virus is a secret attempt by the global elite to reduce overpopulation;

- The virus is a bioweapon by the Chinese state to control the world;

- The virus is a plan by greedy "big pharma" firms to make money from vaccines;

- Eating garlic, drinking hot water, avoiding ice creams or wearing salt-coated facemasks will keep the virus at bay;

- Drinking bleach, chlorine dioxide, colloidal silver or one's own urine can help kill the virus.

Amidst extreme uncertainty, such false, life-threatening information-sadly with the help of many politicians, celebrities, online influencers and key opinion leadersescalated and spread faster than the virus itself in digital media. By mid-February, WHO had to declare the situation as an 'infodemic' that must be fought alongside the fight against the virus itself. As an MIT Technology Review article on Febrary 12 calls it, "the coronavirus is the first true social-media infodemic" (Hao \& Basu, 2020).

Social media giants such as Twitter, YouTube, Facebook and WhatsApp have since expanded their operations in fact-checking, labelling and limiting the sharing of misleading information, including removing fake news, although a study (Brennen, Felix, Howart, \& Nielsen, 2020) found that quite a substantial proportion of such content remains active on their platforms. Further, they work with WHO and national health authorities to prominently feature correct information about the virus and make it easily accessible on their platforms (e.g., Facebook sets up a Covid-19 Information Centre in the news feed of every user or features reputable health sources on top of Covid-19 search results).

\section{A Long-Simmering Crisis}

Such technical interventions might be effective to mitigate the crisis for the time being, but one needs to step back from the Covid-19 pandemic to realise that the ongoing infodemic is not a unique development. Many of the above conspiracy theories are in fact the same old stories being renewed and refashioned in the name of the coronavirus. The $5 \mathrm{G}$ mast attacks, for instance, are just the latest escalation of the anti-5G activist movement that has been spearheaded by Stop $5 \mathrm{G}$ groups around the world. The immune-system suppression claim that leads to recent vandalism is just an extension of the basic theory that anti-5G groups have promoted for years - namely the idea that electro-magnetic radiation from $5 G$ networks has adverse effects on various organs of the human body. Similarly, claims that the new coronavirus is a product of the big pharma's greed or the global elite's effort to control population growth are familiar stories told by anti-vaccination movements in the past decades. Despite being repeatedly discredited and dismissed by national and international health authorities, such claims have featured in every recent international outbreak-such as SARS (2002-2004), H1N1 (2009-2010), MERS (2012-2013), Ebola (2014-2015) and Zika (2015) -and have shown no sign of stopping their contagion soon. What we are witnessing in the current coronavirus infodemic, it seems, is the tipping point of a long-simmering process that facilitates the stubborn refusal to retreat of such false theories-and many other anti-science ones such as climate change denial, Flat Earth and creationism.

In that context, it is important to recognise that the Covid-19 infodemic is not trigged by technological affordances alone. It is true that digital platformswith their omnipresent algorithm and ability to afford emotional support and bias confirmation-make it so easy for mis/disinformation to travel and to engender ill-informed public debates and dangerous decisions (Catalan-Matamoros, 2017; Nguyen \& Vu, 2019; Warren \& Wen, 2016). It would be vastly oversimplified, however, to attribute everything to digital technologies. One, for instance, does not believe that the earth is flat, or deny that anthropogenic global warming exists, or dismiss vaccination as ineffective or dangerous, just because these theories are widely promoted on social media. The fundamental issue remains that many people are still willing to believe in things that, by normal intellectual standards, are unmistakably unscientific or counterintuitive. This is a deep-rooted socio-political problem that has a longer history than the Internet itself. It entails a variety of human factors that can easily cloud public reasoning and/or be skillfully exploited for political, economic and/or religious gains. Among these are existing 
values and beliefs, insufficient health and science literacy, STEM vocation crisis, inadequate news and media literacy, low emotional intelligence, and/or weak ability to be open to different sides of the argument (Coleman, 2018; Rowe \& Alexander, 2017). For instance, prior beliefs can make it very difficult for people to modify false perceptions (Kuklinski, Quirk, Jerit, Schwieder, \& Rich, 2000; Nyhan \& Reifler, 2015). One study even shows that explicit attempts to correct false beliefs with scientific data and facts can backfire, leading individuals to more strongly endorse initial beliefs (Betsch, Renkewitz, $\&$ Haase, 2013).

In other words, digital media act more like an acute catalyst for mis/disinformation to surface in an environment where factual knowledge and evidencebased reasonsing do not always rule. The fight against mis/disinformation about health and science in the digital space, therefore, needs to start from recognising that scientific facts and perspectives-thereby factchecking and correcting information-are far from enough. It needs to put itself in the contemporary socio-cultural contexts in which mis/disinformation thrives-including recent troublesome developments such as the decline of expertise and experts or the rise of post-truth populist politics-and to go deeply into, inter alia, the social psychology of emotions, values and beliefs. Effective dealing with the expanding influx of health and science mis/disinformation, of which the Covid-19 infodemic is the tipping point, requires communication strategies that are "responsive to the needs and attitudes of audiences" and account for the fact that humans are not always logical, calculating or rational (George \& Selzer, 2007, p. 125).

That, in turn, requires deeper understanding of how digital media facilitate or hinder the interaction between rational factual knowledge on one hand and emotions, values and beliefs on the other, and how it shapes public engagement with the health and science issues at stake. Many questions can be asked here. How exactly is mis/disinformation around health and science controversies produced, distributed and redistributed in digital environments? Do-and how do-digital platforms contribute to the decline of the authority of scientific expertise that is already seen in other environments? What techniques and strategies can science journalism and communication employ to tackle the dark sidesand promote the bright sides-of digital media in public communication of science controversies? What are the potential mechanisms for the media, technology firms, the science establishment and the civil society to cooperate in the fight against health and science mis/disinformation?

\section{This Thematic Issue}

The 18 works in this thematic issue contribute to the literature a set of new empirical and theoretical perspectives on the above-including nine full articles around some prominent health and science controversies of our time, as well as nine commentaries based on observations from the first few months of the ongoing Covid-19 crisis.

The first three articles examine anti-science content in digital spaces in three different ways. María Carmen Erviti, Mónica Codina, and Bienvenido León (2020) conducted a content analysis of 826 Google Video search results on three controversial science issues: Climate change, vaccines and nanotechnology. Among the key findings, most returned clips were pro-science or neutral, with only $4 \%$ taking an anti-science stance, and that antiscience videos were more frequent among those produced by ordinary users than by the news media, science institutions, non-science organisations and companies. Quite suprisingly, the presence of scientists does not differ between pro-science, anti-science and neutral clips.

Torben E. Agergaard, Màiri E. Smith, and Kristian H. Nielsen (2020) developed an original qualitative coding framework to analyse prevalent topics and intertextual material (links and shares) in posts generated by the administrators of three Danish Facebook pages that are critical of Human Papillomavirus (HPV) vaccination. They found that these posts assembled different sources (mainstream media, personal anecdotes, political assertions and scientific sources) to construct the messages with a focus on adverse events of HPV vaccination and what posters perceived as inadequate responses of healthcare systems. These Facebook pages, however, are not uniform: they are heterogenous and contextual, responding to and exchanging information and misinformation "within the communication environment in which they are embedded" (Agergaard et al., 2020, p. 339).

Next, Jan Buts (2020) presents two in-depth case studies of a peculiar type of visual content on social media: two popular anti-vaccination memes-namely lists of vaccine ingredients containing mercury, which has been depicted in conspiracy theories as a harmful component of vaccines, and quotes attributed to Mahatma Gandhi, who is known for his condemnation of immunisation. The analysis focuses how the memes moved from the imageboard 4chan to the search engine Google Images, shedding light on how "the repurposed, often ironic use of visual tropes can either undermine or strengthen the claims that accompany them" (Buts, 2020, p. 353). It also pinpoints the intersections of conspiracy theory, visual rhetoric and digital communication-particularly how the ambiguity of memes might serve as vehicles for the dissemination of health mis/disinformation.

The next three articles examine anti- and pro-science communication on social media from user-centred perspectives. Elena Milani, Emma Weitkamp, and Peter Webb (2020) conducted a social network analysis of visual images in Twitter conversations about vaccination. One of their notable findings is that "pro- and anti-vaccination users formed two polarised networks that hardly interacted with each other." Not less im- 
portantly, while anti-vaccination users (primarily parents and activists) "frequently retweeted each other, strengthening their relationships....and confirming their beliefs against immunisation," pro-vaccine users (primarily non-government organisations or health professionals) "formed a fragmented network, with loose but strategic connections" (Milani et al., 2020, p. 364).

Joachim Allgaier (2020) presents an online ethnographic case study of a pre-election YouTube video that attacked the climate change policy of Germany's ruling party, Christian Democratic Union (CDU), and unleashed a heated national online and offline debate. Employing the perspectives of networked forms of expertise and ethno-epistemic assemblages, the author provides a detailed telling account of how a single YouTuber invited fierce attacks from the political establishment, generated strong support from top scientists, networked with other popular German YouTubers into an alliance against CDU or climate-unfriendly far-right parties, and stimulated several months of widespread climate policy debates on other social platforms, mainstream media as well as at schools, churches, arts events and so on.

Asheley R. Landrum and Alex Olshansky (2020) explored why people supported calls for censorship of Flat Earth videos on YouTube, despite the fact that they are believed by few. Their theoretical framework is built around third-person perceptions (people are worried that others, not themselves, are being influenced by such videos) and third-person effects (these worries lead people to support censorship of Flat Earth content on YouTube). In three experiments with American users, they found that third-person perceptions existed and varried strongly with how religious people are and which political party they belong to. However, there was only mixed evidence for whether third-person perceptions predict public support for censoring Flat Earth videos on YouTube.

The last three full articles explore the effects of digital content about health and science controversies on users. Friederike Hendriks and Regina Jucks (2020) investigated whether epistemic uncertainty-which is an essential and integral part of science but has been abused by antiscience activists to cast doubt on whatever they want to dismiss-can influence public perceptions of and attitudes to controversial science issues. In two experiments, they found that introducing epistemic uncertainty about scientific processes into online news articles about climate change did not have a large effect on trust in climate science and scientists or climate decision-making. The presence of uncertainty in the articles, however, did affect the style in which readers reasoned.

Turning attention to framing, a central technique used by science communicators to influence users' perceptions, Sarah Kohler and Isabell Koinig (2020) asked a fundamental turnaround question: As users are fixated to many socio-psychological factors in their background, would they even recognise frames intended by producers? Combining eye-tracking, content analysis and online experiments, they found that users did recognise the health and scientific frames in articles on an Austrian website about Tick-Borne Encephalitis and health frames, being more emotional and less neutral, are more frequently recognised than scientific frames. Moreover, health frame recognition was influenced by most health antecedentes included in their research-including confidence in vacines, health literacy, health consciousness, and health information-seeking behaviours and calculation. The implication, the authors argued, is that health frames can be served as a "fruitful strategy" to create awareness of vaccination and other health issues (Kohler \& Koinig, 2020).

In the last full article, Kaisu Koivumäki, Timo Koivumäki, and Erkki Karvonen (2020) interviewed 17 tweeting and blogging Finnish researchers in the potentially controversial area of renewable energy to investigate what content practices and functions scientists need to adopt online in order to close the sciencesociety gap. The interviewees, they found, were of the general view that scientists as digital science communicators must broaden their trajectories of expertise and communication. More particularly, they should move beyond traditional functions of informing and anchoring facts to adopt "more progressively adjusted practices" such as luring and manoeuvring, including common content tactics by other professional communicators such as buzzwords and clickbait (Koivumäki et al., 2020).

The second part of this thematic issue is a series of nine rapid-response commentaries on the still evolving situation with the Covid-19 pandemic. George Ogola (2020) starts with this an African overview, outlining how mutiple actors - the state, the Church, civil society and the public-generate, in their fight for legitimacy, "a competing mix" of framings, interpretations and narratives about the pandemic, with the consequence being the birth of a new crisis in its own right (Ogola, 2020, p. 440).

Turning to Asia, three national perspectives are presented. Hoa Nguyen and An Nguyen (2020) detail how a chaotic sphere of "the good, the bad and the ugly" - especially rumours, hoaxes and digital incivilityin Vietnam works in a rather strange way to keep its oneparty system on toes and force it to be unusually transparent. Jamie Matthews (2020) reviews a different type of misleading information in Japan: the myth of its cultural exceptionalism, which has been dispersed across the networked public sphere as a factor that helps the country to succeed with the virus. From China, Xin Zhao (2020) observes how its state actors have been using global social platforms as a geo-political battleground during the pandemic, in which they deliberately create a tit-for-tat "Us vs US" narrative with information that is questionable but might nevertheless have gained some influences over users by the time it is scrutinised.

From Italy, the first European country with Covid-19, Alessandro Lovari (2020) focuses on how an erosion of trust in public institutions and the politicization of health and science issues have combined to foster the spread of pandemic misinformation on social media and how the 
Italian Ministry of Health used its official Facebook page to mitigate, to some extent, such spread. In Spain, where science and the media are often treated as properties of the state, Carlos Elías and Daniel Catalan-Matamoros (2020) see two unexpected forces emerging to tell a different truth from that of official sources and media: social networks, especially WhatsApp, and mystery and esotericism TV programmes. From Germany, Holger Wormer (2020), observing a number of atypical shortterm examples, argues that the Covid-19 and its accompanying infodemic have, above all, "accelerated and made more visible existing developments and deficits as well as an increased need for funding of science journalism" (Wormer, 2020, p. 467).

That leads us two the last two perspectives from the US. Sharon Dunwoody (2020) provides a thoughtful analysis of how "copious amounts of uncertainty" associated with Covid-19 can "confuse and mislead publics" (p. 471)-especially with the aid of social media-and how science journalism might play an essential role by privileging scientific sources, fact-checking and doing analytical stories that concentrates on context and promotes understanding. Finally, Emily K. Vraga, Melissa Tully, and Leticia Bode (2020) review recent research to argue that enhancing science literacy and news literacy-especially equipping social media users with the tools to identify, consume and share high-quality information - is a foundational stone to combat Covid-19 mis/disinformation and beyond.

Taken together, this thematic issue sheds some important new light on both the bright and dark sides of digital communication of health and science controversies and offers useful ideas as to how to go from here to mitigate its negatives and foster its positives. We hope that it will invite many questions for future research into an increasingly crucial area that not only safeguards science and improves humanities but also can ultimately save lives.

\section{References}

Agergaard, T. E., Smith, M. E., \& Nielsen, K. H. (2020). Vaccine assemblages on three HPV vaccine-critical Facebook pages in Denmark from 2012 to 2019. Media and Communication, 8(2), 339-352.

Allgaier, J. (2020). Rezo and German climate change policy: The influence of networked expertise on YouTube and beyond. Media and Communication, 8(2), 376-386.

Betsch, C., Renkewitz, F., \& Haase, N. (2013). Effect of narrative reports about vaccine adverse events and biasawareness disclaimers on vaccine decisions: A simulation of an online patient social network. Medical Decision Making, 33(1), 14-25.

Brennen, S., Felix, S., Howart, P., \& Nielsen, R. (2020, April 7). Types, sources and claims of Covid-19 misinformation. Reuters Institute. Retrieved from https:// tinyurl.com/y8lfImer
Buts, J. (2020). Memes of Gandhi and mercury in antivaccination discourse. Media and Communication, 8(2), 353-363.

Catalan-Matamoros, D. (2017). El gran avance del ámbito científico and académico de la comunicación en salud [The great development of the scientific and academic field of health communication]. Revista Española de Comunicación en Salud, 8(2), 114-117.

Cerulus, L. (2020, April 29). How anti-5G anger sparked a wave of arson attacks. Politico. Retrieved from https://www.politico.eu/article/coronavirus-5garson-attacks-online-theories

Clement, J. (2020). Most popular social networks worldwide as of April 2020, ranked by number of active users (in millions). Statista. Retrieved from https://www.statista.com/statistics/272014/globalsocial-networks-ranked-by-number-of-users

Coleman, M. C. (2018). The role of patience in arguments about vaccine science. Western Journal of Communication, 82(4), 513-528.

Dunwoody, S. (2020). Science journalism and pandemic uncertainty. Media and Communication, 8(2), 471-474.

Elías, C., \& Catalan-Matamoros, D. (2020). Coronavirus in Spain: Fear of 'official' fake news boosts WhatsApp and alternative sources. Media and Communication, 8(2), 462-466.

Erviti, M. C., Codina, M., \& León, B. (2020). Pro-science, anti-science and neutral science in online videos on climate change, vaccines and nanotechnology. Media and Communication, 8(2), 329-338.

George, A., \& Selzer, J. (2007). Kenneth Burke in the 1930s. Columbia, SC: University of South Carolina Press.

Hao, K., \& Basu, T. (2020, February 12). The corronavirus is the first true social-media infodemic. MIT Technology Review. Retrieved from https://tinyurl.com/ y8oschng

Hendriks, F., \& Jucks, R. (2020). Does scientific uncertainty in news articles affect readers' trust and decision-making? Media and Communication, 8(2), 401-412.

Kohler, S., \& Koinig, I. (2020). Health and scientific frames in online communication of Tick-Borne Encephalitis: Antecedents of frame recognition. Media and Communication, 8(2), 413-424.

Koivumäki, K., Koivumäki, T., \& Karvonen, E. (2020). “On social media science seems to be more human": Exploring researchers as digital science communicators. Media and Communication, 8(2), 425-439.

Kuklinski, J. H., Quirk, P. J., Jerit, J., Schwieder, D., \& Rich, R. F. (2000). Misinformation and the currency of democratic citizenship. The Journal of Politics, 62(3), 790-816.

Landrum, A. R., \& Olshansky, A. (2020). Third-person perceptions and calls for censorship of Flat Earth videos on YouTube. Media and Communication, 8(2), 387-400. 
Lewis, K. (2020, March 31). $5 \mathrm{G}$ is not accelerating the spread of the new coronavirus. Full Fact. Retrieved from https://fullfact.org/health/5G-notaccelerating-coronavirus

Lovari, A. (2020). Spreading (dis)trust: Covid-19 misinformation and government intervention in Italy. Media and Communication, 8(2), 458-461.

Matthews, J. (2020). "Cultural exceptionalism" in the global exchange of (mis)information around Japan's responses to Covid-19. Media and Communication, 8(2), 448-451.

Milani, E., Weitkamp, E., \& Webb, P. (2020). The visual vaccine debate on Twitter: A social network analysis. Media and Communication, 8(2), 364-375.

Nguyen, A., \& Vu, H. T. (2019). Testing popular news discourse on the "echochamber" effect: Does political polarisation occur among thoserelying on social media as their primacy politics news source? First Monday, 24(6), 1-11.

Nguyen, H., \& Nguyen, A. (2020). Covid-19 misinformation and the social (media) amplification of risk: $A$ Vietnamese perspective. Media and Communication, 8(2), 444-447.

Nyhan, B., \& Reifler, J. (2015). Does correcting myths about the flu vaccine work? An experimental evalua- tion of the effects of corrective information. Vaccine, 33(3), 459-464.

Ogola, G. (2020). Africa and the Covid-19 information framing crisis. Media and Communication, 8(2), 440-443.

Rowe, S., \& Alexander, N. (2017). Food and nutrition science communications: Behind the curtain. Nutrition Today, 52(4), 179-182.

Vestergaard, M. G., \& Nielsen, L. M. (2019). The Danish veterinary and food administration's fight against fake nutrition news on digital media. Journal of Media, Cognition and Communication, 7(2), 46-66.

Vraga, E. K., Tully, M., \& Bode, L. (2020). Empowering users to respond to misinformation about Covid-19. Media and Communication, 8(2), 475-479.

Warren, K. E., \& Wen, L. S. (2016). Measles, social media and surveillance in Baltimore City. Journal of Public Health, 39(3), e73-e78.

Wormer, H. (2020). German media and Coronavirus: Exceptional communication-Or just a catalyst for existing tendencies? Media and Communication, 8(2), 467-470.

Zhao, X. (2020). How China's state actors create a "Us vs US" world during Covid-19 pandemic on social media. Media and Communication, 8(2), 452-457.

\section{About the Authors}

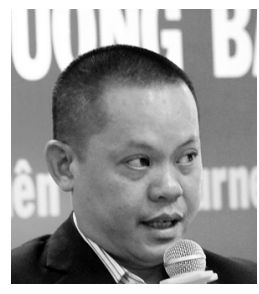

An Nguyen is Associate Professor of Journalism in the Department of Communication and Journalism, Bournemouth University, UK. He has published four books and over 40 papers in several areas: digital journalism, news consumption and citizenship, citizen journalism, science journalism in the post-truth era, data and statistics in the news, and news and global developments. His work has appeared in several journals, among others, Journalism, Journalism Studies, Journalism Practice, Digital Journalism, Public Understanding of Science, International Journal of Media and Culture Politics, Information Research, Journal of Sociology, and First Monday. Prior to academia, he was a science journalist in Vietnam.

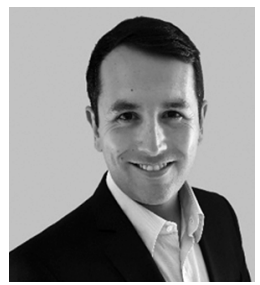

Daniel Catalan-Matamoros (PhD) is a Faculty at the Department of Communication Studies, University Carlos III of Madrid, Spain, and a Researcher of the Health Research Centre, University of Almeria, Spain. In 2020 he was accredited as Full Professor by the Ministry of Universities in Spain. He has led different public health and communication research projects supported by European funding schemes. He has also worked in a variety of national and international public health organizations such as the Spanish Agency of Medicines, the Ministry of Health in Spain, the European Centre for Disease Prevention and Control, and the Regional Office for Europe of the World Health Organization. 